\title{
Spontaneous processes of reproduction of family-based entrepreneurship: an empirical research on the cognitive nature of the spin-offs
}

\author{
Manlio Del Giudice ${ }^{1}$, Maria Rosaria Della Peruta ${ }^{1,2^{*}}$ and Vincenzo Maggioni ${ }^{{ }^{*}}$
}

\author{
* Correspondence: mariarosaria. \\ dellaperuta@unina2.it; vincenzo. \\ maggioni@unina2.it \\ ${ }^{1}$ Second University of Naples, \\ Naples, Italy \\ ${ }^{2}$ Department of Economics, Second \\ University of Naples, Naples, Italy
}

\begin{abstract}
Spin-offs refer to the creation of new firms by employees breaking off from existing firms to give birth to companies of their own. However, this phenomenon has not been predominantly observed in the context of family businesses. Employment in the family firm creates an expectation that family members will act in a manner supportive to the family business: when an employee leaves to become an entrepreneur, parent companies also have to consider whether a spin-off could eventually become a competitor. In this view, when a spin-off process occurs, the parent company could 'gain' a new stakeholder. Cognitive scripts that enable codified knowledge to be transferred to a spin-off may grant the new firm a substantial advantage over the parent company. Therefore, it is assumed that such a stakeholder serves purposes similar to those of the parent company, however assuming a hostile attitude towards the latter. The plausibility of this hypothesis is subsequently tested through multivariate statistical techniques.
\end{abstract}

Keywords: Spin-off, Cognitive scripts, Family business

\section{Background}

In the analysis and interpretation of their own cognitive structure, companies find themselves experiencing today the consequences of two processes started decades ago, which have now reached full maturity. On one hand, the progressive separation and specialization of cognitive domains previously existed in an undistinguished form, within direct operational implementation. On the other hand, a progressive reduction of barriers disturbs and impoverishes the circulation of knowledge among individuals from the same company, hindering access and sharing (Nelson and Winter 1982; Nonaka and Takeuchi 1995). In fact, these two processes have ended up being mutually retroactive: specialized separation has increased the efficiency of cognitive production, ensuring an output better focused on end-users and, therefore, less expensive to attain and deploy. Improved circulation has, however, secured maximum operational efficiency to content, enabling production investment to achieve higher returns and, finally, with a reversal effect, making more resources available for cognitive development. The synthesis of the two processes, by improving the conditions of knowledge use, has ended up generating wide-ranging consequences on the development of the economic activities of the modern enterprise. In this cognitivist 
perspective, it makes little sense to talk about market research and data analysis in business economics if these processes are not aimed at a deeper understanding of an invisible resource such as knowledge, core of innovation, and emblem of the ability to evolve for the enterprise system. This study, with the support of an empirical verification still in progress, examines the importance, for both entrepreneurs and family business managers, of the interpretation of data which can be derived from the processes of entrepreneurship diffusion through the phenomenon of firm creation by spin-off (Leydesdorff 2012; Del Giudice et al. 2011; Carrier 1996; Hellman 2007; Sapienza et al. 2004; Franco and Filson 2006). At the same time, it aims at investigating the complex mechanisms of creation of a possible spin-off script, analyzing, in the light of the evolutionary economics theory and the stakeholder theory, the postspin-off systemic relationships between the spin-off company and the parent organization. Finally, this study highlights the conditions, which the parent company is recommended to monitor, that may spontaneously lead management to spin-off processes.

\section{The study of post-spinoff systemic relationships: from evolutionary economics to the stakeholder theory}

The economic theory known as evolutionary economics was born in opposition to the view of the firm as a production function that aseptically processes input according to given technical coefficients, regardless of the practical knowledge required to obtain the results (Nelson and Winter 1982; Radzicki and Sterman 1994). It is an analytical perspective aimed at investigating the structural dynamics of the economic systems and actors who are part of it, assuming that changes are irreversible, and evolution accomplished until now affects the possible future development paths (path dependency). This line of studies considers, in particular, the role that technological progress has in economic dynamics and pursues the goal of demonstrating the balance of an economic system between static and dynamic efficiency. To explain the role of technology, which is an endogenous variable to the model of economic development of an enterprise, scholars have resorted to the concept of routine. They have viewed the firm as a complex system of routines, and innovation as the product of a new combination of existing routines. The evolutionary economics theory is one of the prodromes of this study. This theory, in fact, assigns a significant relevance to organizational inertia and the consequent importance of past experience, the slowness and difficulty of communicating and sharing tacit knowledge within the firm (Dosi and Marengo 1994; Nelson and Winter 1982; Noteboom and Bogenrleder 2003). The latter is to be found in that part of knowledge that the holder cannot or does not want to express through the available means of representation (natural language, documentation, computer coding, etc.). It is acquired by the individual through practice, and it tends to be the main component of the individual skills mobilized by organizational routines. It is, in itself, a type of procedural and non-declarative knowledge, which is considered unencodable and non-externalizable. It is assumed that tacit knowledge plays a particularly important role in the phenomena of business creation by spin-off, as it would determine more complex and sophisticated behavioral patterns than routines: scripts.

A script is illustrated by the studies of cognitive psychology as a memory structure that represents stereotypical knowledge related to sequences of actions (Gioia and 
Poole 1984; Gioia and Manz 1985). Unlike categories, which are defining and therefore static representations, scripts are dynamic representations of sequences of behaviors associated with a particular context (Abelson 1976; Schank and Abelson 1977). Typical managerial scripts are the modes of analysis of market share and the process of staff selection and purchasing behavior of consumers in a store (from the manager's point of view). In this sense, the concept of organizational routines would seem very close (Nelson and Winter 1982): in fact, scripts have a higher degree of specificity and dynamism and concern micro-behaviors or micro-events. The literature on market research has shown the importance of studying scripts; in fact, they originate from the observation and analysis of a phenomenon that is social before being entrepreneurial: sharing largely tacit knowledge of stereotypical actions with other individuals and generating new knowledge (Del Giudice 2008). Progress made over the years by cognitive psychology (Fisk and Taylor 1991) has attracted a growing interest towards business topics by various scholars committed to verify the applicability of the concept of script in their research. The script theory claims the need and importance of repeating acquired patterns. Moreover, as noted in a research by Tansik and Smith (1991), the repetition of stereotypical actions allows the script to become a habitual behavior, which can simplify and reduce the cognitive effort of the individual in the activation of the process latent in the script (Nottenburg and Shoben 1980). First, the empirical research developed in this study pursues the objective of investigating the importance, for entrepreneurs or managers, of the phenomenon of knowledge accumulation that lead to the creation of a spin-off. It is easy to understand how such knowledge, once it has been definitively acquired by an individual, in so far as it was linked to 'critical' scripts for the preservation of the parent company's competitive advantage, may, ceteris paribus, represent the starting point for the success of the spin-off. Second, it advocates the need to develop market research which is able to seize the possible relationships between the behavior of the new firm created by spin-off and the (spontaneous or induced) genetic process of script sedimentation that led to the spin-off process itself. The study of scripts is, in fact, immediately finalizable to the investigation of market actors, a traditional subject of analysis of market research. Scripts provide indeed an interesting research perspective in the investigation and understanding of the relationship between the enterprise system and certain stakeholders. For example, part of management literature has focused, in particular, on the analysis of the scripts in business-customer relationships (Shurr 1986; Leigh and McGraw 1989).

The present study, however, in an attempt to provide an innovative contribution to management literature, focuses on the relationship between the parent and the spin-off company; in particular, it explores the possible role assumed by the latter in relation to the former. Hence, starting from the stakeholder theory and the assumption that a spin-off may occur as a spontaneous process (that only employees desire) or an induced process (expected also by the parent company), it is possible to theorize three potential attitudes of a spin-off firm towards its parent: hostile, supportive, and non-oriented. In this view, when a spin-off process occurs, the parent company could 'gain' a new stakeholder. For the sake of brevity, our research focuses on companies born by spontaneous spin-off. Therefore, it is assumed that such a stakeholder, by virtue of the 'critical' knowledge scripts synthesized by the new entrepreneurs (ex-employees), serves purposes similar to those of the parent company, however assuming a hostile attitude 
towards the latter. Thus, the spin-off process would give birth to a competitor. The plausibility of this hypothesis is subsequently tested through multivariate statistical techniques.

\section{Results and discussion \\ Exploratory factor analysis}

The hypotheses were tested using the support of multivariate statistical analysis techniques (in the analyses reported, both the SPSS software version 20.0 and LISREL 8.80 were used). An exploratory factor analysis was initially conducted, with the aim of determining which latent variables (items) could be significant for the development of the model and the hypotheses testing. Cronbach's Alpha analysis revealed generally satisfactory levels of internal consistency of the selected items (see Table 1).

Table 1 Exploratory factor analysis

Exploratory factor analysis $\quad$\begin{tabular}{c} 
Scales/items \\
\cline { 2 - 2 } F1 F2 F3
\end{tabular}

Cognitive script acquisition $(a=0.95)$

(1) I consider the use of the know-how acquired one of the main reasons that lead an individual to spin off

(2) I consider confidence in my business idea as one of the main reasons that lead an individual to spin off

(3) I consider technical know-how and training as important factors that lead an individual to 0.91 spin off

(4) I consider personal contacts (developed while working for my company) as important factors that lead an individual to spin off

(5) I consider participating in the development of advanced projects as important factor that 0.84 lead an individual to spin off

Propensity to spin off $(a=0.89)$

(1) I consider the use of the know-how acquired one of the main reasons that lead an individual to spin off

(2) I consider confidence in my business idea as one of the main reasons that lead an individual to spin off

(3) Some individuals in the company are more inclined to promote spin-offs than others

(4) Some functions in the company are more inclined to promote spin-offs than others

(5) The spin-off process has been spontaneously promoted both by the parent company and the employee

Cognitive map reproduction ( $a=0.86$ )

(1) The spin-off firm generally operates in the same industry as the parent company

(2) The spin-off firm generally operates in the same industry as the parent company as service provider

(3) There is generally an average degree of continuity and similarity (know-how and types of technologies used) between the parent company and the spin-off

(4) I consider technical know-how and training as important factors that lead an individual to spin off

(5) The promoters of spin-off processes usually work in 'technical' areas (R\&D, Production); also in the daughter company

Eigenvalue 
The items were later refined and selected to eliminate the latent variables not expressing enough consistency in relation to the proposed model or not exhibiting a high correlation coefficient with other items measuring the same construct. The estimate of the internal consistency of all scales selected on completion of the exploratory factor analysis complied with a cut off loading point $>0.70$ (Nunnally and Bernstein 1994) (Table 1).

\section{Confirmatory model: hypotheses testing and discussion of the empirical results}

The exploratory factor analysis allowed to highlight the relationships between the observed variables and the latent variables required to define the proposed model of entrepreneurship diffusion, based on the spin-off script.

The second part of our empirical analysis, instead, consists of a more detailed study of the derived latent variables, in order to allow the testing of the formulated hypotheses. The confirmatory model was performed on the entire sample (confirmatory dataset) currently available $(n=40)$. The test of hypothesis H1 was carried out by developing a classic confirmatory model ( $\Phi$ test), while that of hypotheses $\mathrm{H} 2$ and $\mathrm{H} 3$ was by a cluster analysis. These choices are perfectly consistent with the indications of management literature on the subject (Gerbin and Anderson 1988).

In the definition of the model, fit ratios showed more than satisfactory values, suggesting the structure of latent variables selected to be maintain unaltered ${ }^{\mathrm{a}}$. The results obtained showed a good internal strength of each identified dimension of the model; likewise, the composite reliability (a measure generated by LISREL, similar to Cronbach's Alpha) returned generally high values (see Table 2). Finally, the variance extracted for each dimension was generally higher than 0.60 , indicating highly shared variance between the indicators of each dimension (Fornell and Lacker 1981) ${ }^{\mathrm{b}}$. Thus, the hypotheses testing leads to the following: Hypothesis H1 starts from the evidence sustained by the literature (Maggioni and Del Giudice 2011) that the accumulation of critical knowledge in a promoter of a spin-off process, who is a family member of a family business, originates from a constant 'exposure' to cognitive scripts that are 'critical' for the company, according to its status. In markets such as those from which the firms in the sample come, the company's governing body is led to promote the

Table 2 Confirmatory model

\begin{tabular}{|c|c|c|c|}
\hline & \multicolumn{3}{|c|}{$\Phi$ Estimates $^{\mathrm{a}}$} \\
\hline & \multicolumn{3}{|c|}{ Dimensions of the model } \\
\hline & 1 & 2 & 3 \\
\hline Cognitive script acquisition (1) & 1.00 & & \\
\hline \multirow[t]{2}{*}{ Propensity to spin off (2) } & 0.75 & 1.00 & \\
\hline & $(21.51)^{b}$ & & \\
\hline \multirow[t]{2}{*}{ Cognitive map reproduction (3) } & 0.87 & 0.77 & 1.00 \\
\hline & $(19.52)^{b}$ & $(14.27)^{\mathrm{b}}$ & \\
\hline Standard deviation & 1.21 & 1.47 & 1.65 \\
\hline Composite reliability & 0.87 & 0.82 & 0.89 \\
\hline Variance extracted & 0.42 & 0.64 & 0.51 \\
\hline
\end{tabular}

${ }^{a}$ The first number indicates the value assumed by the phi coefficient. The second is the value assumed by $t$.

bSignificant at the level $p<0.01$. 
circulation of knowledge in the operational structure, with the aim of increasing the resonance of the enterprise system. This involves a necessary increase in the transfer of tacit and explicit knowledge between individuals in the operational structure. Especially in family businesses, family members more easily come in contact with critical processes to support the competitive advantage of the company and share information and contacts which are vital for its management. Therefore, it will be easier for them to manage these processes in developing behavioral scripts that can reduce the cognitive effort inherent in the activation process over which they preside (Maggioni and Del Giudice 2011).

This would lead to a spontaneous entrepreneurial process that has at its basis the reproduction of the parent company's cognitive map. Hypothesis H1, while highly correlating that capacity of synthesizing a cognitive script with the latent constructs 'propensity to spin off' and 'cognitive map reproduction', of course does not exclude coparticipation in the spin-off process of the classical motivations that lead an individual towards independent entrepreneurship (desire for more prestige, increased income, greater autonomy, confidence in one's own business idea possibly not shared by family members, etc.). The critical point in the development of the empirical analysis was, therefore, to prove first of all the existence of a possible correlation between the accumulation of knowledge (of which the cognitive script acquisition is a direct expression) and the propensity to spin off, linked to a precise determination of the new entrepreneur to reproduce the parent company's cognitive map. The confirmatory model developed (Table 2) clearly shows these close correlations (cognitive script acquisition, propensity to spin off $(\Phi=0.75)$; cognitive script acquisition, cognitive map reproduction $(\Phi=0.87))$, demonstrating the ability of the individual holding the scripts to turn from employee to entrepreneur, following the 'footprints' of the parent company's success. Thus, the model consists of two moments: the first, in which the holder of certain knowledge aspires to develop outside of the family business, and the second in which the family member concerned with the spin-off attempts (even only potentially) to reproduce in his spin-off firm the critical knowledge accumulated in the parent company. Such knowledge makes up the cognitive map of a process that the new entrepreneur considers vital for the new company. The confirmatory model provided a valid support for hypothesis $\mathrm{H} 1$, showing an undoubtedly high value of the $\Phi$ coefficient in the correlation between the various constructs (Table 2).

Hypotheses $\mathrm{H} 2$ and $\mathrm{H} 3$ allow, instead, to capture more nuances of the process described and provide an interesting interpretation of the post-spin-off relations between the companies involved in the spin-off process. Hypothesis $\mathrm{H} 2$, in particular, argues that spin-off firms may assume a hostile attitude, supportive or non-oriented, towards the parent company. The test required the use of cluster analysis. The analysis initially used a hierarchical clustering procedure, conducted with Ward's method and the Euclidean squared distance. Later, the technique of multiple discriminant analysis (MDA) and multivariate analysis of variance were applied at the same time as the post hoc Scheffe test (designed to reach a reliable estimate of the internal consistency of the groups covered by the classification). The results of the multivariate analysis of variance, developed in conjunction with the MDA, revealed distinctive characteristics for each of the three clusters obtained. The correlation between the latent variables of the model (Bartlett test of sphericity $=137.5$ with $9 \mathrm{df}, p<0.0001$ ) confirmed, moreover, the 
appropriateness of the choices made for the multivariate data analysis (it was all further supported by positive results from Pillai's test, Hotelling's $T^{2}$, Wilks' lambda, all expressing significant values at the level $p<0.000$ ). The final result, which confirmed hypothesis $\mathrm{H} 2$ in the first place, is given by the existence of three different types (clusters) of spin-off firms, arising from the cognitive script acquisition process in the family businesses investigated (Tables 3 and 4).

MDA and multivariate analysis of variance showed that all latent variables contribute to significantly differentiate clusters $(p<0.0001)$, and this is confirmed by the fact that the two discriminant functions arising from the MDA exert, respectively, 53.2\% and $46.8 \%$ of the total variance between clusters. In particular, the discriminating factor and group centroids clearly show that function 1 discriminates cluster I from clusters II and III, whereas function 2 distinguishes cluster II from clusters I and III. Moreover, the hit ratio $(=77.50 \%)$ indicates that almost $80 \%$ of the cases investigated were classified correctly. ${ }^{\mathrm{c}}$ At this point, through the $F$-ratio, it is possible to show more in depth the characteristics of the clusters and test hypotheses $\mathrm{H} 2$ and $\mathrm{H} 3$ (Table 5).

The cluster analysis developed allowed the identification of three spin-off clusters, consistently with hypothesis H2. The relationships shown in Table 5 allow, moreover, an immediate verification of hypothesis $\mathrm{H} 3$ itself: spin-off firms with hostile postspinoff attitude towards the parent company are born from a strictly 'spontaneous' spin-off script.

\section{Conclusions}

The empirical verification conducted in this study highlights the need that family business governance manages knowledge flows and the conditions of internal entrepreneurship of the operational structure in an efficient and timely manner. Constant support of

Table 3 Summary of multiple discriminant analysis results

\begin{tabular}{|c|c|c|c|c|}
\hline & \multicolumn{2}{|c|}{ Discriminant loadings } & \multicolumn{2}{|c|}{ Group centroids } \\
\hline & Function 1 & Function 2 & Function 1 & Function 2 \\
\hline Spin off support by the parent company ${ }^{a}$ & 0.59 & 0.57 & & \\
\hline Spontaneous propensity to spin off & 0.41 & 0.49 & & \\
\hline Business continuity with the parent company & 0.59 & 0.44 & & \\
\hline Intensity of post spin-off relations & 0.75 & -0.68 & & \\
\hline Cluster I & & & 1.42 & 0.73 \\
\hline Cluster II & & & -0.35 & -1.34 \\
\hline Cluster III & & & -1.81 & 1.56 \\
\hline Eigenvalue & & & 1.72 & 1.49 \\
\hline Percentage of variance & & & $51.7 \%$ & $42.5 \%$ \\
\hline Canonical correlation & & & 0.837 & 0.751 \\
\hline Wilks' lambda & & & 0.179 & 0.346 \\
\hline Chi-square & & & 82.0 & 119.8 \\
\hline Significance & & & 0.000 & 0.000 \\
\hline
\end{tabular}

${ }^{a}$ The scales shown were obtained from the exploratory factor analysis previously illustrated in Table 1, reduced in size. For the sake of brevity, the observed variables related to the individual constructs have been omitted. Only $a$ Cronbach values for the latent variables are shown, all perfectly in line with the expected cut-off level $(C T L>0.70)(a$ values were $0.77,0.73,0.84$, and 0.91 , respectively). 
Table 4 Predicted group membership values

\begin{tabular}{lcccc}
\hline $\begin{array}{l}\text { Classification } \\
\text { of actual } \\
\text { group }\end{array}$ & $\begin{array}{l}\text { Number } \\
\text { of cases }\end{array}$ & I & Predicted group membership & II \\
\cline { 3 - 5 } & 11 & 9 & 1 & 1 \\
\hline Cluster I & $94.56 \%$ & $3.40 \%$ & $2.04 \%$ \\
Cluster II & 24 & 3 & 20 & 1 \\
Cluster III & 5 & 1 & $91.72 \%$ & $1.00 \%$ \\
& & $3.03 \%$ & 1 & 3 \\
Hit ratio $89.4 \%^{\mathrm{a}}$ & & $7.50 \%$ & $89.47 \%$ \\
\hline
\end{tabular}

${ }^{a}$ As it is well-known, the hit ratio, the percentage of correctly classified cases, is given by the sum of the predicted membership values divided by the sum of the resulting cases belonging to the different clusters. In this case, $\mathrm{HR}=[(9+20+3) /(11+24+5)] \times 100=77.50 \%$.

the enterprise system to entrepreneurship development and effective monitoring of the spin-off firms possibly launched by family members will be vital to manage quasimarket relationships and fuel the parent company's competitive advantage through a collaborative management of the spin-off. The gradual consolidation, even unconscious, of the cognitive map latent to business processes by members of the operational structure belonging to the owner family, together with the high degree of autonomy granted to them, can lead to the development of more direct conditions for the creation of spin-off firms. Faced with such a scenario, particularly adherent to the evolutionary paradigm of Italian family-run SMEs, this study helps to understand the need that corporate governance reconciles the diffusion of internal entrepreneurship among family members with the risk of transferring firm-specific skills to 'non-supportive' companies. If, on the one hand, in fact, market analysis of inter-organizational relationships between parent and spin-off companies confirms the ability of spin-off promoters to generally undertake the role of stakeholders in relation to the enterprise system, it is also true that this role may be played by the spin-off firm for various reasons and in different ways (supportive, hostile, non-oriented). The research has shown that in the case of the creation of spontaneous spin-off scripts, there is a significant risk for the parent company to have unconsciously transferred vital knowledge to a highly probable competitor. Thus, one of the major empirical findings of the proposed model lies in the opportunity offered to a family entrepreneur to reconcile his goal of disseminating knowledge within the company, pursuing the creation of a fully integrated operational structure, though there is the possible risk of creating, albeit unconsciously, the conditions for triggering a hostile spin-off process by family members, which disperse the company's vital knowledge to the benefit of future competitors. The study of the determinants of the scripts underlying spin-off processes helps predict the hypothetical future relations with the spin-off companies and their possible attitude towards the parent company. Closer monitoring of the internal knowledge flows and a better management of the scripts exerting processes which are 'critical' for the enterprise will help the entrepreneur manage the spin-off processes in order to integrate the spin-off firms in a 'quasi-market' relationship with the parent company. In essence, it will allow the development of a collaborative relationship aimed at creating a family 'meta-organization'. 
Table 5 Characteristics of the clusters

\begin{tabular}{|c|c|c|c|c|c|}
\hline \multirow[t]{2}{*}{ Scales } & \multicolumn{3}{|c|}{ Mean scores and standard deviations ${ }^{a}$} & \multirow{2}{*}{$\begin{array}{c}F- \\
\text { ratio }\end{array}$} & \multirow[t]{2}{*}{ Significance } \\
\hline & $\begin{array}{c}\text { Supportive } \\
\text { (cluster I, } n=11 \text { ) }\end{array}$ & $\begin{array}{c}\text { Non-supportive } \\
\text { (cluster II, } n=24 \text { ) }\end{array}$ & $\begin{array}{c}\text { Mixed blessing } \\
\text { (cluster III, } n=5 \text { ) }\end{array}$ & & \\
\hline $\begin{array}{l}\text { Spin-off support by the } \\
\text { parent company }\end{array}$ & $2.7(0.78)$ & $0.4(0.94)$ & $1.7(1.3)$ & 42.6 & 0.000 \\
\hline $\begin{array}{l}\text { Spontaneous propensity } \\
\text { to spin off }\end{array}$ & $0.7(0.96)$ & $2.9(0.83)$ & $1.6(1.8)$ & 35.4 & 0.000 \\
\hline $\begin{array}{l}\text { Business continuity with } \\
\text { the parent company }\end{array}$ & $2.3(0.74)$ & $0.6(0.92)$ & $2.5(0.91)$ & 59.8 & 0.000 \\
\hline $\begin{array}{l}\text { Intensity of postspin-off } \\
\text { relations }\end{array}$ & $2.5(0.64)$ & $0.6(0.72)$ & $1.8(1.5)$ & 14.8 & 0.000 \\
\hline
\end{tabular}

${ }^{\mathrm{a}}$ The standard deviations are the values inside the parentheses.

\section{Methods}

One of the nodal stages of the empirical research was the identification of the target audience. The research was conducted from July 2012 to January 2013 and involved the administration of an interview carried out in the form of a semistructured questionnaire with both closed and open questions. The sample consisted of active enterprises with headquarters in the Italian region Campania, the provinces of which have distinctive homogeneous features with regard to family business spin-off processes (Del Giudice et al. 2011). The study started from an almost total absence of data on the number of family businesses in Campania. It proved to be particularly difficult in the initial development and definition of the research modelling. Therefore, the starting point was the sample selection. Active enterprises were extracted from the database of the Chambers of Commerce of the five Campania provinces (Naples, Caserta, Avellino, Benevento, and Salerno). To simplify the research process, an analysis was conducted on the master data and the balance sheets (if available) of 50 partnerships and corporations, the business names of which could be related to a surname (e.g., 'Amarelli Ltd.'), chosen from each of ten industries deemed representative by the management literature and the regional statistics:
(1) Food
(2) Manufacturing
(3)Construction
(4)Commerce
(5) Tourism
(6) Transport
(7) ICT
(8)Credit and insurance
(9) Business services
(10) Personal services

If the principle nomen est omen is true, there would have been a good chance that among the companies investigated, a high percentage of family businesses 
would have been identified. Business choices also had to meet the following criteria:

- Establishment prior to the year 1982 (purpose of identifying multigenerational family businesses);

- State of activity at the time of the survey;

- Balanced economic and financial development over the years (purpose of identifying businesses);

- Presence in the shareholding structure of at least two members with the same surname (purpose of identifying family shareholding structures). Of course, the presence of members with the same surname is not a sufficient cause for a family business, but it can be a suitable indicator to narrow the field of investigation, with all the limitations and the lability related to it.

Another limitation that helped further narrow the research was any coincidence of surname between the main administrator/entrepreneur at the time of the firm's establishment and the current one. Unfortunately, the available data and the need for economies of time in the conduction of the research have not always allowed to verify this coincidence, which, of course, has only provided a rough indicator. The selection of the sample would have required additional factors and stages of refinement and alignment, but for time saving reasons, it was necessary to consider the sample obtained as sufficiently representative. This certainly highlights the limits of this research; however, it leaves wide space for future investigation on the matter. Hence, a database was created containing information from 500 alleged family businesses. The data were collected through the administration of a structured online questionnaire made of 46 questions, using ASP script coupled to a freeware SQL Server technology-based database resident on a dedicated server (Figure 1$)^{\mathrm{d}}$.

The representatives of the population of firms previously identified during the sampling phase were invited to respond by e-mail to the online questionnaire. The survey was also supported by several in-depth interviews. The formulation and testing of the hypotheses developed benefited from the decisive contribution of multivariate statistical analysis, allowing rigorous methodological conclusions to be reached. Respondents had access to dedicated pages, and as the number of interviews increased, data were automatically collected by the database. A special online section was also created, which shows the results of the interviews, updated in real time, through some basic processing of descriptive statistics (three-dimensional bar charts, pie graphs, radar charts, etc.). The database and the online questionnaires were, in fact, attached to a simple statistical processor that allows the monitoring (in real time) of the progress of the interviews, providing an immediate empirical result with a simple and intuitive graphic layout (Figure 2).

The possibility of taking part in the study was offered to all 500 companies belonging to the selected sample, which freely and voluntarily agreed to join the research, assigning a member of their top management to the administration of the questionnaire. The collection of information required for the subsequent statistical analysis was carried out in advance by sending an e-mail (or a fax, if e-mail was not available) in which the survey was presented to all companies belonging to the sample, demanding 


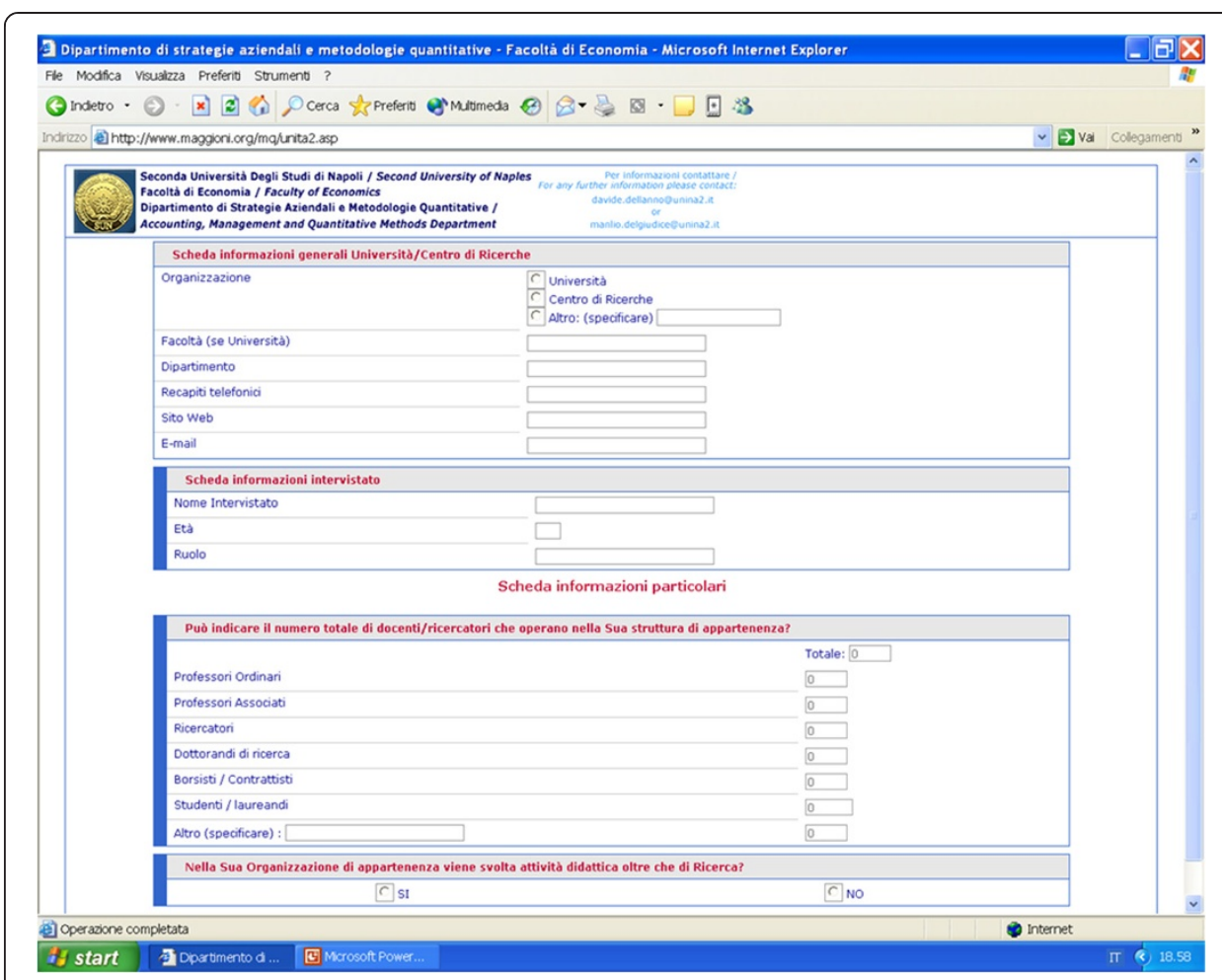

Figure $1 \mathrm{~A}$ page of the online questionnaire (www.maggioni.org).

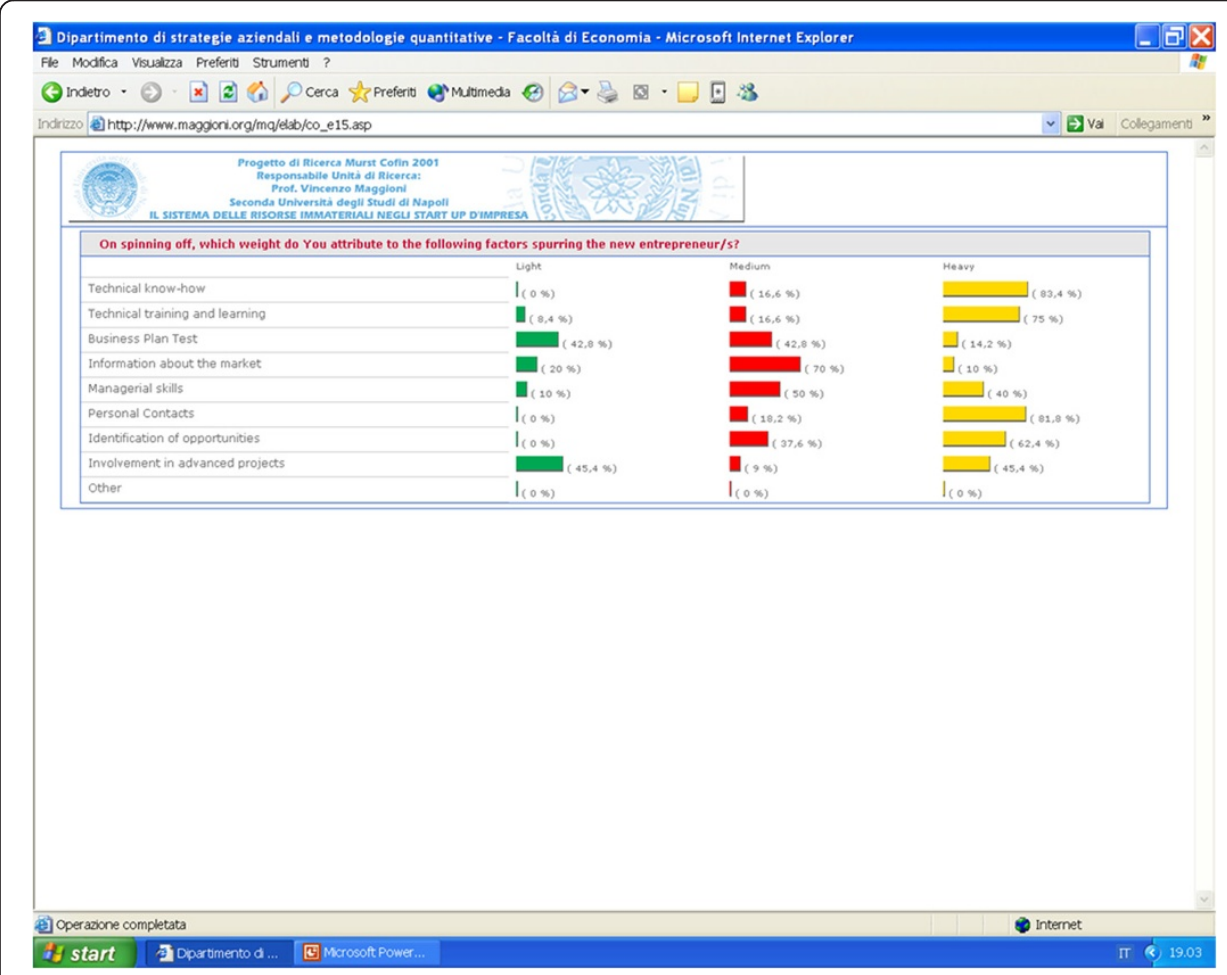

Figure 2 A page of the online Results Presenter (www.maggioni.org). 
the availability to take part in the survey. The link to the web page to be accessed in order to fill out the online questionnaire was sent by email to the companies that confirmed their interest to participate in the survey. The questionnaire posed a dual filter question: if the company was indeed a family business and if in the last ten years it had been involved in spin-off events (in various ways). It was also asked whether the respondent was interested to take part in the survey. If the answer to one of the two filter questions was negative, the interview was over. In a nutshell, the main results of this phase were as follows:

- 327 companies confirmed their interest to participate in the survey (among the remaining, 121 did not respond at all, and 52 responded that they were not interested in participating);

- Among these 327 companies, 297 responded affirmatively to the first filter question (concerning the nature of family business of the interviewed enterprise), confirming the validity of the research design developed; 11 reported a sudden impossibility to participate in the survey; and 19 cases gave unjustified lack of responses (even after a second reminder);

- Among the 297 family businesses selected, 109 responded affirmatively to the second filter question (regarding the involvement in spin-off events in various ways over the last ten years).

The results from 109 companies representing the sample of firms investigated were as follows:

- 78 completed questionnaires (considered to be valid during the data encoding phase);

- 12 incomplete questionnaires (not considered valid in the data encoding phase);

- 5 answers of sudden impossibility to participate in the survey;

- 14 unjustified absences of response (even after a second reminder).

Thus, the final answering rate (which only takes account of the questionnaires to be considered valid for the purpose of research) can be quantified in $71.5 \%$ of the investigated sample. It should be pointed out that the questions were not asked in the process of sending the e-mail containing the invitation to participate in the survey, in order to avoid as much as possible distortions and false responses. The survey, of course, is not immune to this risk, within the responses regarding the statement of non-family business. The collected data were coded in MS Excel grids, treated in an aggregate manner and processed with the aid of SPSS statistical software version 20.0 for Windows 2010.

Following the sampling phase, standard procedures of scale definition were developed, with regard to the identification of multidimensional latent variables of the cognitive spin-off scripts. The scales for the spin-off scripts were identified on the basis of the guidelines suggested by Churchill (1979) and Gerbin and Anderson (1988). In the definition of the latent variables, also different techniques were used at the same time, such as in-depth interviews with entrepreneurs and business managers. Observed and latent variables initially obtained were critically analyzed ${ }^{e}$. Subsequently, in order, the total correlation of the items obtained, verification of Cronbach's alpha, 
and an exploratory factor analysis were performed ${ }^{\mathrm{f}}$. Hence, the initial items were redefined, and those considered non-significant were removed.

\section{Hypotheses underlying the research design}

Below, the main research hypotheses underlying the model described so far are formalized and explained. In particular,

H1: exposure to 'critical' scripts leads family members ${ }^{\mathrm{g}}$ to a spontaneous process of reproduction, in a new company (spin-off script), of the cognitive map acquired H2: spin-off firms launched by family members may assume a hostile attitude, supportive or non-oriented, towards the parent company H3: spin-off firms launched by family members assuming a hostile attitude towards the parent company are born from 'spontaneous' spin-off scripts

\section{Endnotes}

${ }^{\mathrm{a}}$ Despite $\chi^{2}$ returning statistically high values $\left(\chi^{2}=34.47, \mathrm{df}=39, p<0.01\right)$, other fit ratios confirmed the full acceptability of the model (Tucker-Lewis Index $=0.81$ and comparative fit index $=0.94$; Bollen 1989). Moreover, it is a common knowledge that $\chi^{2}$ is strongly affected by the size of the selected sample.

${ }^{\mathrm{b}}$ In this study, for the sake of simplicity, the values of the $\chi^{2}$ difference test will be omitted, all of which returned fully satisfactory values.

${ }^{c}$ The latent variables and the performed clustering are perfectly consistent with the theoretical models in the literature (Davenport and Prusak 1998). This confirms the validity of the model developed since Aldenderfer and Blashfield (1984) also proved that the accuracy in the classification of cases (indicated by a high hit ratio) is a necessary condition for the reliability of clustering, but it is not also a sufficient condition to affirm the validity of the latter. In order to ascertain the validity of the model, it is always necessary to cross the empirical data obtained by clustering, with the arguments put forward by the most qualified literature to verify if the positions actually coincide.

${ }^{\mathrm{d}}$ The data acquisition system is based on an ASP database which can be directly filled out on the website www.maggioni.org.

'This study takes into account only a few dimensions of the spin-off model deemed significant. Therefore, it omits the description of the selection of all possible derived scales/items, object of later publications. In fact, the possible variables of the questionnaires used were approximately 1,200 , giving a statistically significant amount of data covering different aspects of the research, and it would have been useless to include them in this analysis. Similarly, the exploratory analysis returned several other scales/ items, focusing on different angles and perspectives of the research study. For the sake of simplicity, only the variables in the text closely related to the hypotheses to be tested will be reported.

${ }^{\mathrm{f}}$ To avoid using the same sample both in the exploratory analysis and the confirmatory model, the sample was ideally split into two data sets: (a) an exploratory data set of 69 units on which the exploratory factor analysis was performed and (b) a confirmatory data set of 40 units on which the confirmatory model was developed. 
'The reference to a 'family member' is to be understood as 'family member of a family business'. Therefore, he is an individual belonging to the family that owns the family business, works as a partner or employee, and launches a spin-off.

\section{Competing interest}

The authors declare that they have no competing interests.

\section{Authors' contributions}

MRDP authored the background, the summary literature review, and conclusions. MDG structured the research methodology and performed the results and discussion. VM conceived of the study and participated in its design and coordination. All authors read and approved the final manuscript.

Received: 2 May 2013 Accepted: 9 May 2013

\section{Published: 12 June 2013}

\section{References}

Abelson, R. (1976). Script processing in attitude formation and decision making. In JS Carrol e \& JW Payne (Ed.), Cognition and social behavior (pp. 33-45). Hillsdale, NJ: Erlbaum.

Aldenderfer, MS, \& Blashfield, RK. (1984). Cluster analysis. Beverly Hills, CA: Sage.

Bollen, KA. (1989). Structural equations with latent variables. New York: Wiley.

Carrier, C. (1996). Intrapreneurship in small businesses: An exploratory study. Entrepreneurship Theory and Practice, 21(1), $5-20$

Churchill, GA, Jr. (1979). A paradigm for developing better measures of marketing constructs. Journal of Marketing Research, 16(1), 64-73.

Davenport, TH, \& Prusak, L. (1998). Working knowledge. How organizations manage what they know. Boston: Harvard Business School Press.

Del Giudice, M. (2008). L'impresa pensante. Torino: Giappichelli.

Del Giudice, M, Della Peruta, MR, \& Carayannis, EG. (2011). Knowledge and the family business. The governance and management of family firms in the new knowledge economy. Series: Innovation, technology and knowledge management. NY: Springer.

Dosi, G, \& Marengo, L. (1994). Some elements of an evolutionary theory of organizational competencies. In RW England (Ed.), Evolutionary concepts in contemporary economics (pp. 157-178). Ann Arbor: Michigan University Press.

Fisk, S, \& Taylor, S. (1991). Social cognition. New York: McGraw-Hill.

Fornell, CR, \& Lacker, DF. (1981). Two structural equation models with unobservable variables and measurement error. Journal of Marketing Research, 18, 39-50.

Franco, A, \& Filson, D. (2006). Knowledge diffusion through employee mobility. RAND Journal of Economics, 37, 841-860.

Gerbing, DW, \& Anderson, JC. (1988). An updated paradigm for scale development incorporating unidimensionality and its assessment. Journal of Marketing Research, 25, 186-192.

Gioia, DA, \& Manz, C. (1985). Linking cognition and behavior. A script processing interpretation of vicarious learning. Academy of Management Review, 10(3), 527-539.

Gioia, DA, \& Poole, PP. (1984). Scripts in organizational behaviour. Academy of Management Review, 9, 449-459.

Hellman, T. (2007). When do employees become entrepreneurs? Management Science, 53(6), 919-933.

Leigh, T, \& McGraw, P. (1989). Mapping the procedural knowledge of industrial sell personnel: a script-theoretic investigation. Journal of Marketing, 53(1), 16-34.

Leydesdorff, L. (2012). The triple helix, quadruple helix, ..., and an $n$-tuple of helices: Explanatory models for analyzing the knowledge-based economy? Journal of Knowledge Economy, 3, 25-35.

Maggioni, V, \& Del Giudice, M. (2011). Affari di famiglia: problematiche gestionali e modelli imprenditoriali emergenti nei nuovi family business. Milano: EGEA.

Nelson, RR, \& Winter, S. (1982). An evolutionary theory of economic change. Cambridge: Harvard University Press.

Nonaka, I, \& Takeuchi, H. (1995). The knowledge creating organization: how Japanese companies create the dynamics of innovation. New York: Oxford University Press.

Noteboom, B, \& Bogenrleder, I. (2003). Change of routines: a multi-level analysis (ERIM Report Series). ERS-2003-029-ORG.

Nottenburg, G, \& Shoben, E. (1980). Scripts as lineal orders. Journal of Experimental Social Psychology, 16, 329-347.

Nunnally, JC, \& Bernstein, IH. (1994). Psychometric theory (3rd ed.). New York, NJ: McGraw-Hill.

Radzicki, M, \& Sterman, JD. (1994). Evolutionary economics and system dynamics. In R England (Ed.), Evolutionary concepts in contemporary economics (pp. 61-89). Ann Arbor: University of Michigan Press.

Sapienza, H, Parhankangas, A, \& Autio, E. (2004). Knowledge relatedness and post-spin-off growth. Journal of Business Venturing, 19(6), 809-829.

Schank, R, \& Abelson, R. (1977). Scripts, plans, goals and understanding. Hillsdale: Erlbaum.

Shurr, P. (1986). Four script studies: what we have learned. In R Lutz (Ed.), Advances for consumer research (Vol. 13, pp. 498-503). Provo (UT): Association for Consumer Research.

Tansik, D, \& Smith, W. (1991). Dimension of job scripting in services organization. International Journal of Service Industry Management, 2(1), 35-49.

doi:10.1186/2192-5372-2-12

Cite this article as: Del Giudice et al:: Spontaneous processes of reproduction of family-based entrepreneurship:

an empirical research on the cognitive nature of the spin-offs. Journal of Innovation and Entrepreneurship 2013 2:12. 